\title{
KOLABORASI GURU-DOSEN DALAM PENELITIAN TINDAKAN KELAS UNTUK MENINGKATKAN HASIL BELAJAR SISWA
}

\author{
Sukatiman', Roemintoyo1, Chundakus H¹, M. Akhyar'1, Sutikno², Suwarno ${ }^{3}$ \\ Fakultas Keguruan dan Ilmu Pendidikan Universitas Sebelas Maret Surakarta \\ SMK Negeri 1 Mondokan Sragen \\ SMK Negeri 5 Surakarta \\ E-mail; sukatiman@fkip.uns.ac.id
}

\begin{abstract}
Lecturers have broad autonomy in developing instructional. With the characteristics possessed by these lecturers, collaboration between lecturers (team teaching) is a challenge that is sometimes not easy. However, in vocational learning, lecturer cooperation in learning is something that cannot be avoided. In the Classroom Action Research to SMK, researchers collaborated at partner schools of SMKN 5 Surakarta and SMKN I Mondokan Sragen. The type of research used is ethnographic research, which is a qualitative observation method used in social science that focuses on field studies and their interactions, and sees everything as unique. The method used in conducting the evaluation is the equivalent test, which is a test that aims to measure its reliability identically with the reference test. The conclusion that can be drawn in this PDS program is to complement each other's strengths and weaknesses in organizing the learning process for SMK. Pamong teachers who work together are senior teachers who have eaten a lot of salt in their teaching. Pamong teachers have adequate competence in teaching and educating students, on the other hand, senior teachers have limitations in developing learning innovations. This is where the role of PDS lecturers in completing the shortage of teachers. The innovation that the lecturers did was to provide guidance using e-learning in learning at SMK. This e-learning has many advantages in learning the millennial generation. By maintaining student motivation, the learning objectives will be better achieved.

Keywords; Collaboration of Teachers and Lecturers, Classroom Action Research, Learning Outcomes
\end{abstract}

\section{PENDAHULUAN}

Untuk mewujudkan revitalisasi pendidikan Lembaga Pendidikan Tenaga Kependidikan (LPTKP) maka pemerintah telah melaksanakan program penugasan dosen ke sekolah (PDS). Program tersebut memiliki tujuan diantaranya untuk memberikan pengalaman bagi dosen dalam memahami perkembangan pendidikan di SMK, sehingga diharapkan dapat meningkatkan profesionalitas guru dan dosen dalam mengajar.

Menurut (Undang-Undang No 14 tahun 2005, 2005), seorang dosen harus memiliki kompetensi yang meliputi kompetensi pedagogik, professional, kepribadian, dan sosial. Dari keempat kompetensi tersebut, yang paling banyak mendapatkan kritik adalah kompetensi pedagogik, terutama kemampuan dalam menyampaikan materi dengan menggunakan metode yang menarik dan efektif atau yang disebut dengan active learning (pembelajaran aktif). Dalam (PP No 19 tahun 2005, 2005), tentang Standar Nasional Pendidikan (SNP) terdapat pernyataan yang menekankan pada penggunaan pembelajaran aktif: "Proses pembelajaran pada satuan pendidikan diselenggarakan secara interaktif, inspiratif, menyenangkan, menantang, memotivasi peserta didik untuk berpartisipasi aktif, serta memberikan ruang yang cukup bagi prakarsa, 
kreativitas, dan kemandirian sesuai dengan bakat, minat, dan perkembangan fisik serta psikologis peserta didik."

Sejalan dengan penguasaan kompetensi oleh guru dan dosen, maka terdapat istilah yang secara internasional telah diakui sebagai salah satu metode dalam meningkatkan kompetensi dosen yaitu TPACK. Technological Pedagogical Content Knowledge (TPACK) merupakan konsep mengajar yang merupakan integrasi dari teknologi, strategi mengajar, dan penguasaan materi, yang harus dikuasai oleh dosen untuk dapat melaksanakan PBM secara efektif (Koehler, Mishra, \& Cain, 2017).

Penelitian tentang pembelajaran online pada K-12 (setingkat SLTA) menunjukkan bahwa pengetahuan keguruan (paedagogycal) dan isi materi (contain knowledge) adalah yang paling tinggi. Pada saat yang sama guru merasa kurang percaya diri pada domain teknologi (ICT) (Archambault \& Crippen, 2009). Hal ini dapat dartikan bahwa guru belum sepenuhnya menguasai 3 domain profesinya. Terdapat hubungan erat antara profesionalitas dosen dengan pengalaman mengajar, dimana dosen pada awal karier lebih tertarik pada kurikulum dan pembelajaran, sedangkan dosen pada akhir karier (generesai boomer) lebih berminat pada bidang ekstrakurikuler dan inovasi (Louws, et al. 2017). Dengan meningkatkan TPACK, dosen akan dapat menjawab permasalahan pembelajaran masa kini yang memerlukan kreatifitas dan inovasi pembelajaran.

Kerangka kerja dosen terhadap integrasi teknologi, paedagogi, dan isi materi (TPACK) dapat digambarkan pada gambar 1 berikut.

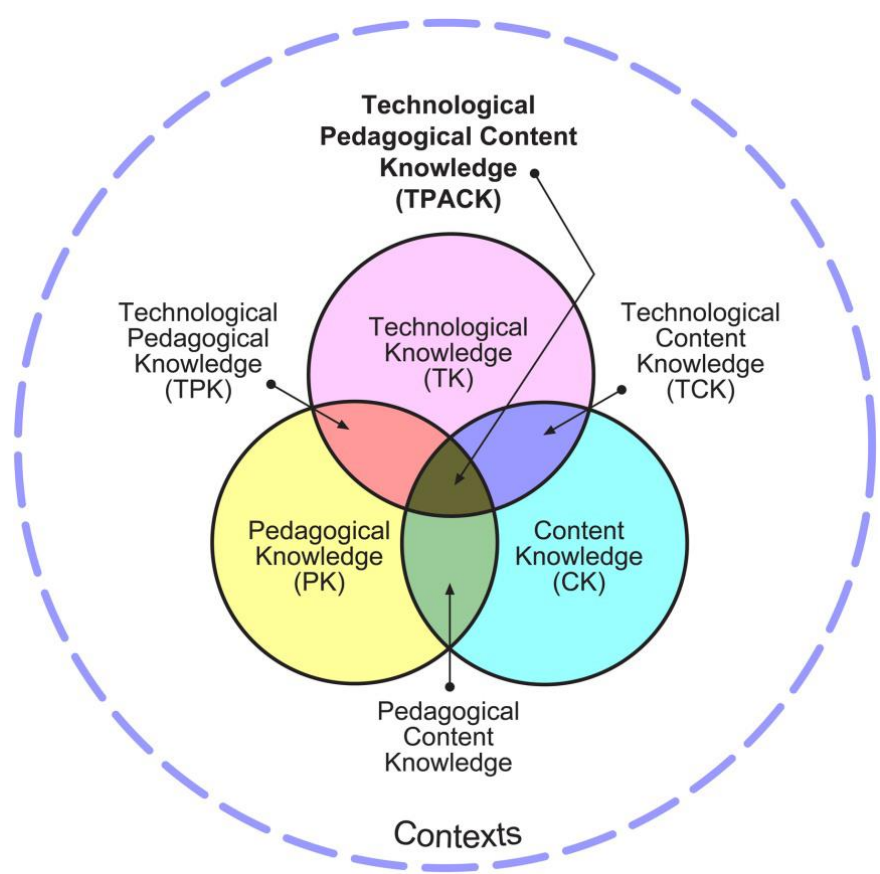

Gambar 1. The TPACK framework and its knowledge components. 
(Beverborg, Sleegers, \& Van Veen, 2015), menjelaskan terdapat 3 macam cara untuk mengembangkan profesionalitas dosen, yaitu:

1) Selalu menjaga kegiatan pembelajaran, termasuk kemajuan dan keajegan keahlian melalui literatur, dan selalu mengembangkan metode pembelajaran, mengembangkan kurikulum dan mengembangkan pendidikan secara umum. Menjaga kekinian melalui informasi dan pandangan luar sebagai bagian profesionalitas dosen secara individu.

2) Profesionalitas pembelajaran dijaga melalui suatu percobaan dengan adaptasi melalui pembelajaran praktis terkini untuk merubah pandangan lama.

3) Profesionalitas pembelajaran dengan refleksi pribadi, dimana profesionalitas dikreasi ulang untuk mendapatkan pengalaman baru

\section{Kerjasama Dosen sebagai Tim}

Dalam suatu pembelajaran kelas, dosen lebih banyak bekerja sebagai individu. Dosen memiliki otonomi luas dalam mengembangkan instruksionalnya. Dengan karakteristik yang dimiliki dosen tersebut, kerjasama antar dosen (team teaching) menjadi tantangan yang terkadang tidak mudah. Namun demikian dalam pembelajaran vokasi, kerjasama dosen dalam suatu pembelajaran menjadi suatu hal yang tidak bisa dihindari. Hal ini dikarenakan sifat materi yang memerlukan peralatan praktik yang hanya bisa memfasilitasi beberapa siswa. Dengan demikian pembagian kelas menjadi kelompok-kelompok kecil dengan melibatkan beberapa dosen dengan tujuan pembelajaran yang sama, akan lebih efektif dilaksanakan agar kompetensi pembelajaran dapat tercapai.

Dalam Penelitian Tindakan Kelas ke SMK, peneliti melakukan kolaborasi pada sekolah mitra SMKN 5 Surakarta dan SMK N I Mondokan Sragen. Sebagaimana hubungan dengan sekolah mitra, maka guru yang dipilih menjadi mitra kerja juga sudah berhubungan baik cukup lama, sehingga diharapkan penelitian akan dapat berjalan dengan baik. Kemitraan yang menjadi pilihan adalah guru yang mengajar Ilmu Ukur Tanah/Survei dan pemetaan. Observasi terhadap pembelajaran didapatkan adalah :

1) Hasil pembelajaran masih dilaksanakan dengan 1 kelas penuh (34 siswa) dengan job yang sama, hal ini tentu akan memiliki ketidakefektifan mengingat peralatan yang terbatas, sehingga 1 alat dipakai oleh lebih dari 10 siswa. dari permasalahan tersebut maka peneliti merencanakan pembelajaran dengan membagi kelas dalam kelompok yang lebih kecil (kelas dibagi 2 kelompok besar = 18 siswa). dari kelompok besar ini dibagi dalam dua macam materi, yaitu a) materi praktik dengan alat sederhana, yang peralatannya seperti yalon, unting-unting, rol meter, dan kompas, dan b) praktik dengan kelompok penggunaan pesawat penyipat datar (PPD), yaitu praktik belajar menggunakan alat pemetaan jenis optis. 
2) Observasi berikutnya, peneliti menemukan bahwa, materi belum diberikan kepada siswa secara terencana, sehingga diperlukan pembenahan perencanaaan materi agar dapat tersampaikan kepada siswa secara dini. E-learning menjadi pilihan terbaik untuk dapat memberikan materi yang dapat diakses oleh siswa secara sederhana dengan mobile phone yang sudah dimiliki oleh seluruh siswa. pada awalnya guru ragu-ragu untuk memberikan ijin kepada siswa meggunakan mobile phone untuk pembelajaran. Hal ini disebabkan guru khawatir dengan memanfaatkan mobile phone pembelajaran justru tidak efektif, karena siswa akan memanfaatkan gadget untuk media sosial. Setelah melalui diskusi tentang pentingnya penggunaan media dalam mendukung pembelajaran abad-21, yang juga disukai anak-anak generasi milenial, sehingga guru harus dapat melihat karakteristik siswa belajar, maka guru dengan senang hati mensuport pembelajaran dengan mmemanfaatkn mobile learning. Dengan memanfaatkan smartphone untuk pembelajaran, maka akan meningkatkan motivasi siswa belajar.

Dari hasil observasi kelas, diketahui bahwa semua siswa memiliki mobile phone yang dapat dipakai untuk aplikasi program, dan aplikasi edmodo adalah pilihan untuk melengkapi media pembelajaran bagi sisiwa SMK. Dengan disetujuinya rencana saya tersebut, kemudian saya merancang pembelajaran sebagai berikut:

Jadwal Praktik Pengukuran Tanah untuk SMK Negeri 5 Surakarta Kelas: X

\begin{tabular}{|c|c|c|c|c|c|}
\hline \multirow{2}{*}{$\begin{array}{c}\text { Mingg } \\
\text { u Ke }\end{array}$} & \multicolumn{2}{|c|}{$\begin{array}{l}\text { Kelompok Ganjil dengan alat } \\
\text { sederhana }\end{array}$} & \multirow{2}{*}{$\begin{array}{l}\text { Mingg } \\
\text { u ke }\end{array}$} & \multicolumn{2}{|c|}{$\begin{array}{c}\text { Kelompok Genap dengan pesawat } \\
\text { PPD }\end{array}$} \\
\hline & \multicolumn{2}{|c|}{$\begin{array}{c}\text { Tugas siswa } \\
\end{array}$} & & & Tugas siswa \\
\hline 1 & $\begin{array}{l}\text { Membuat } \\
\text { garis lurus } \\
\text { di } \\
\text { lapangan } \\
\text { dengan } \\
\text { alat } \\
\text { sederhana }\end{array}$ & $\begin{array}{ll} & \text { Menegakkan } \\
& \text { yalon. } \\
\circ & \text { Mengukur jarak } \\
\circ & \text { Mengukur } \\
\text { sudut } \\
\circ & \text { Mengikat ke } \\
\text { titik permanen } \\
\text { di lapangan } \\
\circ & \text { Menggambar } \\
\text { peta }\end{array}$ & 1 & $\begin{array}{l}\text { Membuat } \\
\text { garis lurus } \\
\text { di } \\
\text { lapangan } \\
\text { dengan } \\
\text { alat } \\
\text { sederhana }\end{array}$ & $\begin{array}{ll}\circ & \text { Menegakkan yalon. } \\
\circ & \text { Mengukur jarak } \\
\circ & \text { Mengukur sudut } \\
\circ & \text { Mengikat ke titik } \\
& \text { permanen di } \\
& \text { lapangan } \\
\circ & \text { Menggambar peta }\end{array}$ \\
\hline 2,3 & $\begin{array}{l}\text { Memetaka } \\
\mathrm{n} \text { profil } \\
\text { memanjan } \\
\mathrm{g}\end{array}$ & $\begin{array}{ll} & \text { Membuat garis } \\
& \text { lurus } \\
\circ & \text { Mengukur jarak } \\
\text { setiap station } \\
\circ & \text { Mengukur } \\
\text { ketinggian } \\
\text { station } \\
\circ & \text { Mengitung beda } \\
& \text { tinggi } \\
\circ & \text { Menghitung } \\
\text { ketinggian }\end{array}$ & 2,3 & $\begin{array}{l}\text { Pengenala } \\
\text { n alat sipat } \\
\text { datar } \\
\text { dengan } \\
\text { cara } \\
\text { mengukur } \\
\text { beberapa } \\
\text { target } \\
\text { dengan } \\
\text { sudut dan } \\
\text { jarak yang }\end{array}$ & $\begin{array}{ll} & \text { Mendirikan statif. } \\
\circ & \text { Mengenal bagian2 } \\
& \text { pesawat penyipat } \\
& \text { datar (PPD) } \\
\circ & \text { Mendatarkan } \\
& \text { pesawat } \\
\circ & \text { Membidik target } \\
\circ & \text { Mendokumentasika } \\
& \text { n data } \\
\circ & \text { Menghitung } \\
\circ & \text { Menggambar }\end{array}$ \\
\hline
\end{tabular}




\begin{tabular}{|c|c|c|c|c|c|}
\hline & & $\begin{array}{l}\text { Menggambarka } \\
\text { n peta }\end{array}$ & & $\begin{array}{l}\text { berbeda- } \\
\text { beda, } \\
\text { dengan } 1 \\
\text { target } \\
\text { untuk } \\
\text { masing- } \\
\text { maasing } \\
\text { siswa } \\
\end{array}$ & \\
\hline 4,5 & $\begin{array}{l}\text { Memetaka } \\
\text { n profil } \\
\text { melintang }\end{array}$ & 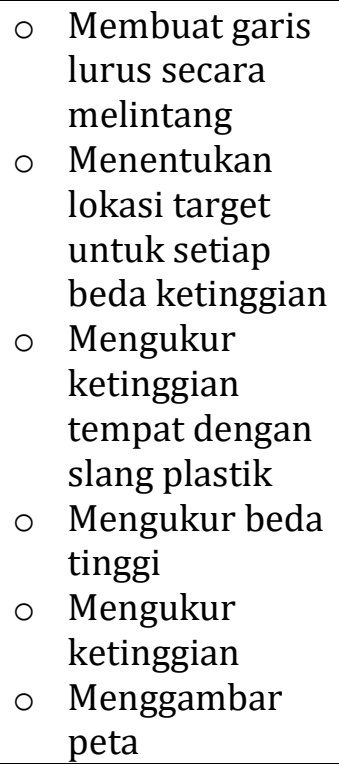 & 4,5 & $\begin{array}{l}\text { Memetaka } \\
\text { n profil } \\
\text { memanjan } \\
\text { g }\end{array}$ & $\begin{array}{ll} & \text { Mendirikan pesawat } \\
\circ & \text { Membidik 1 target } \\
& \text { profil depan } \\
& \text { belakang } \\
\circ & \text { Mencatat hasil } \\
\circ & \text { Menghitung } \\
\circ & \text { menggambar }\end{array}$ \\
\hline 6,7 & $\begin{array}{l}\text { Membuat } \\
\text { bouplank } \\
\text { dengan } \\
\text { alat } \\
\text { sederhana }\end{array}$ & $\begin{array}{ll} & \text { Membaca } \\
& \text { gambar } \\
\circ & \text { Meluruskan } \\
\circ & \text { Menyiku } \\
\circ & \text { Mendatarkan } \\
\circ & \text { Mengukur }\end{array}$ & 6,7 & $\begin{array}{l}\text { Memetaka } \\
\text { n profil } \\
\text { melintang }\end{array}$ & $\begin{array}{ll}\text { o } & \text { Mendirikan pesawat } \\
\text { o } & \text { Membidik 1 target } \\
& \text { profil depan } \\
& \text { belakang } \\
\text { o } & \text { Mencatat hasil } \\
\text { o } & \text { Menghitung } \\
\text { o } & \text { Menggambar }\end{array}$ \\
\hline
\end{tabular}

\section{METODE}

Jenis penelitian yang digunakan adalah jenis penelitian etnografi, yaitu metode observasi kualitatif yang digunakan pada ilmu sosial yang berfokus pada kajian lapangan dan interaksinya, serta melihat segala sesuatu sebagai hal yang unik,(https://en.wikipedia.org/wiki/Ethnography, 2018). Ciri dari penelitian etnografi ini diantaranya adalah penelitian dengan kasus yang tidak luas, data tidak terkonstruksi (induktif), lebih memfokuskan laporan temuan di lapangan dibanding mengintepretasi data.

Metode yang dipergunakan dalam pelaksanaan evaluasi adalah tes ekuivalen, yaitu suatu tes yang hendak mengukur reliabilitasnya secara identik dengan tes acuan. Setiap tampilannya, kecuali substansi item yang ada, dapat berbeda. Evaluasi tersebut mempunyai karakter yang sama. Karakteristik yang dimaksud misalnya mengukur variabel yang sama, mempunyai jumlah item sama, struktur sama, mempunyai tingkat kesulitan dan mempunyai petunjuk, cara 
penskoran, dan interpretasi yang sama (Sukardi, 2008). Pernyataan serupa juga disampaikan oleh (Arikunto, (1997: 87)yang menyatakan bahwa tes paralel atau equivalent adalah dua buah tes yang mempunyai kesamaan tujuan, tingkat kesukaran dan susunan, tetapi butir-butirnya berbeda. Istilah ini dikenal dengan nama Alternate-forms method (parallel forms).

Pelaksanaan tindakan diawali dengan pemberian pendalaman PTK oleh dosen kepada beberapa guru sekolah SMKN Mondokandan SMK N 5 Surakarta. Pelaksanaan tindakan kemudian dilaksanakan pada sekolah SMKN 5 Surakarta, mengingat lokasi yang memungkinkan untuk kolborasi. Tim teaching (Dosen PTB, Guru SMK Mondokan dan Guru SMKN 5 Surakarta melakukan observasi dan membantu pelaksanaan pembelajaran.Penelitian dilakukan pada kelas 1A, yang sedang mengikuti praktik Dasar-Dasar Konstruksi Bangunan dan Teknik Pengukuran pada Konstrentrasi Disain Pemodelan dan Informasi Bangunan (DPIB) , SMKN 5 Surakarta.

Dari latar belakang masalah, diketahui bahwa kelas terdiri dari 33 siswa, kelas ini kemudian dibagi dalam 2 kelompok besar (17 siswa kelompok Idan 17 siswa kelompok 2) untuk mendapatkan peralatan praktik yang memadai yaitu peralatan sederhana dan peralatan berbasis optis (PPD). Untuk mendapatkan ciri pertama dari pembentukan ketrampilan V-HOT, siswa dibagi dalam kelompok kecil yaitu 7 siswa. Dengan memperkecil anggota kelompok, maka masing-masing siswa memiliki peran yang lebih nyata dalam praktik. Kelompok kecil ini diberi tugas:1) latihan menggunakan alat Pesawat Penyipat datar (PPD), 2) melakukan pengukuran sudut beberapa target dengan cara optis dan membandingkan dengan pengukuran manual (rol meter, 3) pengukuran memanjang 4) pengukuran penampang melintang.

Untuk memudahkan dalam mengambil data penelitian, maka dilakukan pengkodean pada sumber data, untuk siswa praktik diberi kode S1-sampai S4 sesuai dengan jumlah siswanya dalam kelompok. Kode A1 sampai dengan A4 menunjukkan asisten siswa yang berjumlah 4 orang. kode I1 dan I2 adalah kode untuk instruktur pembimbing praktik hari tersebut, demikian juga kode Tl untuk toolman laboratorium. Untuk pengkodean kelompok praktik dibagi dua yaitu WTG (kelompok Wild T0) dan TG untuk (kelompok Topcon).

\section{HASIL DAN PEMBAHASAN}

\section{Pelaksanaan Pembelajaran}

Dari hasil survei didapatkan hasil bahwa lokasi praktik di SMKN 5 sudah sangat terbatas, terutama semua permukaan tanah hampir semua sudah dibetonisasi. Dibutuhkan inovasi pembelajaran untuk mendapatkan lokasi yang memungkinkan untuk praktik. Pada minggu pertama disepakati bahwa lokasi praktik di lokasi sebelah gedung teori belakang Perpustakaan pusat ddengan materi praktik membuat garis lurus. Selengkapnya dapat dilihat pada RPS. Personil pembimbing terdiri dari dosen PDS sendiri dibantu oleh siswa yang melakukan penelitian untuk skripsi 2 orang, dan 2 orang guru pamong.Pada pelaksanaan praktik minggu 
pertama ini, siswa masih kebingungan untuk melakukan praktik. Dengan dibimbing secara teliti oleh 5 orang instruktur, siswa dapat melakukan praktik mendirikan jalon,membuat garis lurus di lapangan, membuat skets dengan lancar. Setelah selesai praktik siswa istirahat siang untuk Istirahat.Pada pukul 13.00 siswa masuk kelas dan mendiskusikan hasilnya bersama teman satu kelompok, dan mewujudkan dalam laporan perseorangan, dengan format: 1. Materi, tujuan, peralatan yang dibutuhkan, langkah kerja, dan kesimpulan. Semua materi dapat dilihat di Edmodo yang dapat diakses oleh siswa melalui smartphone.

Setelah siswa selesai membuat laporan kemudian hasilnya dikumpulkan dan di bahas untuk didiskusikan oleh instruktur dan guru pamong. Hasil refleksi menunjukkan bahwa pada praktik pertama tersebut semua siswa masih butuh perhatian untuk pembiasaan mengoperasikan peralatan. Pelaksanaan praktik minggu kedua, kelompok grup praktik di bagi 2, yaitu 1 grup yang terdiri 3 kelompok praktik 5-6 orang, praktik menggunakan peralatan sederhana, dengan materi membuat garis lurus dan menentukan beda tinggi. Grup 2 yang teridiri dari 3 kelompok (5-6) orang melaksanakan praktik pengenalan alat sipat datar (PPD). Pada pelaksanaan praktik dengan alat sederhana, para siswa sudah mulai terbiasa menggunakan peralatan sehingga tidak canggung lagi. Pembimbingan lebih diarahkan untuk melakukan praktik yang lebih akurat, dan juga bagaimana mengaktifkan siswa untuk terlibat secara aktif saling bekerjasama.

Pada pelaksanaan praktik grup 2, yang menggunakan pesawat PPD, para instruktur bekerja keras agar siswa memahami bagian-bagian dari pesawat, dan melakukan penyetelan dengan benar dan berhati-hati. Kehati-hatian dalam menggunakan alat ini penting agar alat tidak cepat rusak. Pada pelaksanaan praktik dengan PPD ini target yang dikenakan kepada siswa, adalah setiap siswa dapat membaca bacaan benang dengan akurat, baik untuk mengitung jarak maupun beda tinggi. Refleksi dari pembelajaran minggu kedua ini adalah, siswa butuh bantuan pembimbingan yang lebih efektif untuk dapat menyetel PPD.

Setelah istirahat dilakukan pembimbingan membuat laporan, materi dapat didownload dari aplikasi edmodo melalui smartphone siswa. Namun demikian, siswa mencatat ulang peralatan yang dibutuhkan dan langkah kerjanya dengan di tulis tangan. Langkah ini diperlukan agar siswa lebih memahami apa yang sudah dipraktikkan. Pelaksanaan praktik minggu ke tiga, topik yang dipraktikkan masih sama dengan peserta praktik saling bertukar materi praktik. Grup praktik yang minggu lalu memakai alat sederhana, pada pertemuan ini memakai alat sipat datar (PPD) dan sebaliknya yang minggu lalu praktik memakai PPD sekarang praktik dengan alat sederhana.Pada minggu ke 4 dan ke 5, kelompok PPD melakukan praktik dengan topikmemetakan profil memanjang. Mengingat lokasi sekolah sudah tidak memungkinkan untuk membuat profil memanjang, maka praktik dilakukan di depan sekolah SMK N 5. Praktik mengambil lokasi jalan lambat di depan sekolah yang cukup nyaman. Materi praktik dapat dilihat 
pada RPS.Sedangkan untuk grup alat sederhana melaksanakan praktik dengan membuat profil memanjang pada daerah bangunan perpustakaan.

Pada minggu ke 6 dan 7, grup PPD melaksanakan praktik dengan materi membuat profil melintang, sedangkan grup alat sederhana, membuat bouwplank/ staking out dengan penjelasan materi terlampir. Pada pelaksanaan praktik ini model pembelajaran yang digunakan adalah problem based learning (PBL), dengan kemampuan awal yang sudah dimiliki siswa, yaitu membuat garis lurus, membuat garis siku dengan pitagoras, dan membuat kedataran dengan slang plastik. Hasilnya menunjukkan bahwa siswa benar-benar sudah dapat melakukan praktik dengan keterampilan yang cukup memadai.

Pada minggu ke delapan siswa di minta untuk membuat laporan yang dilaksanakan pada minggu ke 7, mengingat praktik minggu ke 7 memerlukan waktu sampai sore, sehingga pelaporan dikerjakan pada minggu ke 8.

\section{Analisis Data}

Hal menarik dalam penugasan dosen ke SMK adalah terbukanya wawasan dosen untuk dapat melihat SMK secara dekat, dimana lulusan SMK harus dibekali kompetensi yang HOTS (berpikir tingkat tinggi). Untuk mendapatkan V-HOTS tersebut, pengajar harus merencanakan pembelajaran bagi siswa secara aktif. Untuk mengaktifkan siswa belajar tersebut harus dilakukan oleh pengajar dengan persiapan yang matang. Cara mengefektifkan pembelajaran bagi siswa dapat dilakukan dengan menyiapkan format-format yang dibagikan kepada kelompok agar memudahkan siswa untuk mengisikan data praktiknya. Hal kedua adalah proses pengayakan siswa, guru dan dosen harus merancang kompetensi siswa dengan memperhatikan HOT. Kisi-kisi HOTS yang disusun guru sebagai berikut:

Tabel 2. Penilaian Tindakan (Proses mendapatkan Ketrampilan V-HOT)

\begin{tabular}{|l|l|c|c|c|l|}
\hline No & \multicolumn{1}{|c|}{ Item yang dinilai } & $\begin{array}{c}\text { Level } \\
\text { HOT }\end{array}$ & Bobot & $\begin{array}{l}\text { Skor } \\
\text { Capaian }\end{array}$ & $\begin{array}{l}\text { Bobot } \\
\text { x skor }\end{array}$ \\
\hline 1 & $\begin{array}{l}\text { Memperkirakan kebutuhan alat } \\
\text { yang akan dipakai. }\end{array}$ & C2 & 8 & 75 & 624 \\
\hline 2 & $\begin{array}{l}\text { Menyebutkan bagian dan fungsi } \\
\text { alat. }\end{array}$ & C3 & 10 & 78 & 780 \\
\hline 3 & Penyetelan ketegakan PPD penyetelan garis & C4 4 & 10 & 80 & 700 \\
\hline 4 & $\begin{array}{l}\text { Melakukan } \\
\text { Horisontal dan arah sudut kompas }\end{array}$ & C4 & 13 & 65 & 936 \\
\hline 5 & Menganalisis kebutuhan data & C5 & 15 & 78 & 1170 \\
\hline 6 & $\begin{array}{l}\text { Menganalisis ketelitian data bidikan } \\
\text { target }\end{array}$ & C4 & 13 & 70 & 910 \\
\hline 7 & $\begin{array}{l}\text { Mengkomunikasikan data dengan } \\
\text { standar SNI dan merefleksi }\end{array}$ & C6 & 18 & 85 & 1530 \\
\hline 8 & Pelaporan & & & \\
\hline
\end{tabular}




\begin{tabular}{|l|l|l|l|l|l|}
\hline & & & & & 7625 \\
\hline
\end{tabular}

Keterangan :

$$
\begin{array}{llll}
\mathrm{C} 1 & =\text { Mengingat } & \mathrm{C} 4 & =\text { Menganalisis } \\
\mathrm{C} 2 & =\text { Memahami } & \mathrm{C} 5 & =\text { Mengevaluasi } \\
\mathrm{C} 3 & =\text { Mengaplikasi } & \mathrm{C} 6 & =\text { Berkreasi }
\end{array}
$$

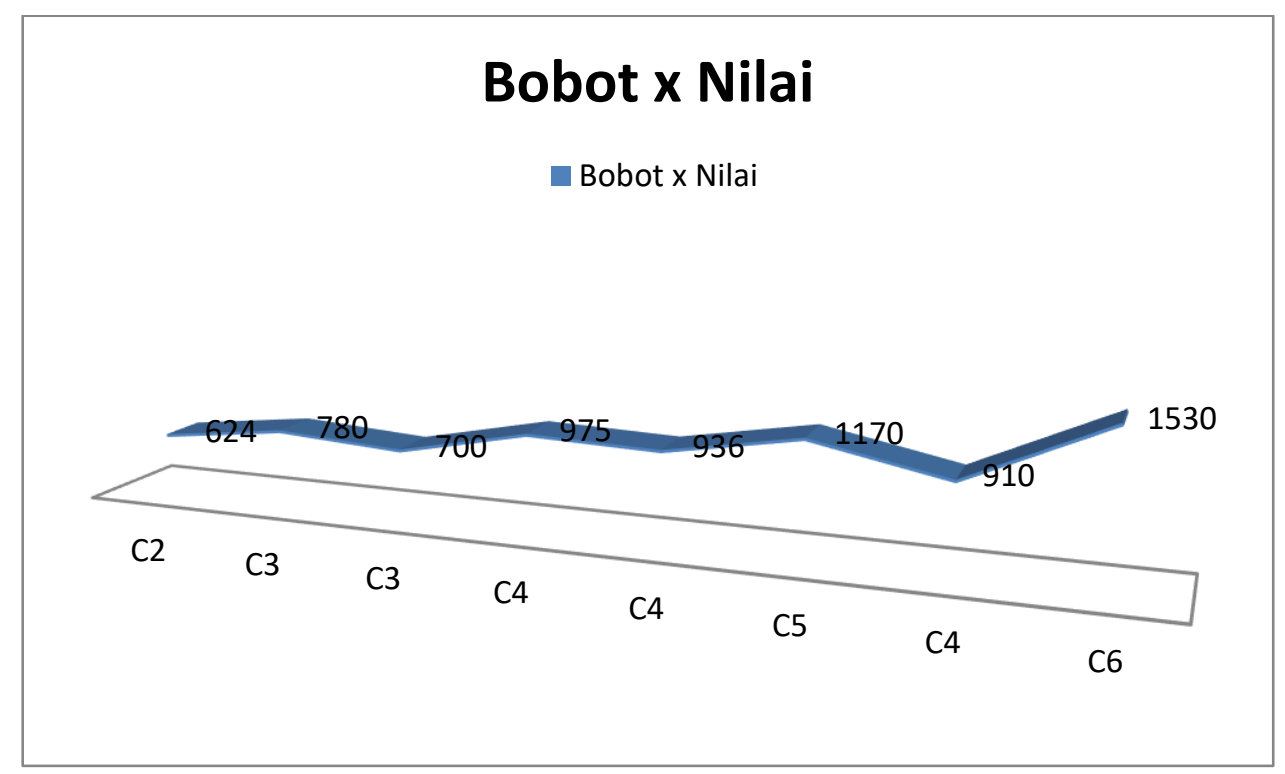

Gambar 2. Pembentukan Scff-PBL siswa (V-HOT)

Dengan perencanaan penilaian tindakan yang didesain menggunakan prinsip HOTS, menunjukkan bahwa siswa mendapatkan ilmu yang lebih merata dari kognitif tingkat rendah (LOT) yang terdiri dari 1) memperkirakan kebutuhan peralatan yang akan digunakan sudah dikuasai.Pada item 2) menegakkan statif PPD masih butuh pembimbingan untuk minggu-minggu berikutnya agar siswa lebih kompeten dalam menyetel nivo untuk ketegakan sudut horisontal dan lebih teliti dalam membidk sudut jurusan . Pada kognitif tingkat tinggi (HOT) untuk item penyetelan garis horisontal dan sudut kompas sudah cukup baik, namun untuk item ketelitian bidikan masih butuh pembimbingan agar dapat lebih teliti apabila dibandingkan dengan ketelitian SNI. Untuk item pelaporan, siswa lebih kreatif dalam berdiskusi dengan temantemannya, sehingga penguaaan HOT sudah baik.

Penilaian tindakan tersebut dibarengi dengan penilaian sikap proaktif siswa selama mengikuti praktik. Ketidak aktifan siswa ini akan dipakai untuk membedakan nilai kelompok dan 
nilai individu, sehingga akan terjadi kolaborasi praktik antara siswa yang aktif untuk bisa mensuport siswa yang kurang aktif. Keaktifan individu yang dinilai meliputi 1) aktif dalam berdiskusi, 2) memiliki sikap proaktif pada waktu praktik, 3) kerjasama dengan team, 4) tanggung jawab, 5) jujur, 6) keselamatan kerja selama praktik. Penilaian tindakan ini dilakukan 3 kali untuk melihat apakah pembentukan V-HOT sudah tercapai sesuai dengan KKM yang ditetapkan sekolah.

\section{KESIMPULAN}

Pelajaran berharga yang dapat diambil hikmahnya dengan program PDS ini adalah saling mengisi kelebihan dan kekurangan dalam menyelenggarakan proses pembelajaran bagi SMK. Guru pamong yang bekerjasama adalah guru senior yang sudah banyak makan asam garam dalam mengajar. Guru pamong memiliki kompetensi yang memadai dalam mengajar dan mendidik siswa, disisi lain guru senior memiliki keterbatasan dalam mengembangkan inovasi pembelajaran. Disinilah peran dosen PDS dalam melengkapi kekurangan guru. Inovasi yang dosen lakukan adalah dengan memberikan bimbingan menggunakan e-learning dalam pembelajaran di SMK. E-learning ini memiliki banyak kelebihan dalam pembelajaran generasi milenial. Dengan menjaga motivasi siswa maka tujuan pembelajaran akan tercapai dengan lebih baik.

\section{ACKNOWLEDGMENT}

Untuk meningkatkan pembelajaran bagi siswa SMK, maka peneliti memberikan saran sebagai berikut:

1. Praktik ukur tanah sebaiknya dilaksanakan pada semester ganjil, mengingat pada saat ini terdapat siswa PPL. Siswa PPL tersebut dapat dimanfaatkan untuk membantu guru dalam mengawasi praktik.

2. Gunakan e-learning untuk membantu siswa belajar lebih lama, dan dimanapun dengan memanfaatkan smartphone siswa.

3. Permudahlah kerja siswa dengan menyiapkan format-format isian data praktik.

4. Tingkatkan HOTS siswa dengan perencanaan dan persiapan guru yang lebih baik.

\section{BIBLIOGRAFI}

Archambault, L., \& Crippen, K. (2009). Examining TPACK among K-12 online distance educators in the United States. Contemporary Issues in Technology and Teacher Education, 9(1), 71-88. https://doi.org/10.1080/0158791022000009213

Arikunto, S. (1997). Prosedur Penelitian suatu Pendekatan.

Beverborg, A. O. G., Sleegers, P. J. C., \& Van Veen, K. (2015). Promoting VET teachers' individual 
and social learning activities: The empowering and purposeful role of transformational leadership, interdependence, and self-efficacy. Empirical Research in Vocational Education and Training, 7(1), 1-20. https://doi.org/10.1186/s40461-015-0018-4

Koehler, M. J., Mishra, P., \& Cain, W. (2017). What is Technological Pedagogical Content Knowledge (TPACK)? Journal of Education, 193(3), 13-19. https://doi.org/10.1177/002205741319300303 PP No 19 tahun 2005 (2005). Sukardi. (2008). Metodologi Penelitian Pendidikan, Kompetensi dan Praktiknya. Undang-Undang No 14 tahun 2005, 48 § (2005). 